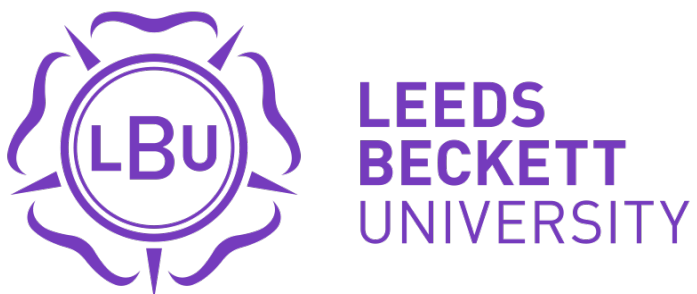

Citation:

Piso, A (2014) Migrant Labour in Rural Tourism: Continuity and Change. International Journal of Tourism Research, 18 (1). 10 - 18. ISSN 1099-2340 DOI: https://doi.org/10.1002/jtr.2020

Link to Leeds Beckett Repository record:

https://eprints.leedsbeckett.ac.uk/id/eprint/1366/

Document Version:

Article (Accepted Version)

The aim of the Leeds Beckett Repository is to provide open access to our research, as required by funder policies and permitted by publishers and copyright law.

The Leeds Beckett repository holds a wide range of publications, each of which has been checked for copyright and the relevant embargo period has been applied by the Research Services team.

We operate on a standard take-down policy. If you are the author or publisher of an output and you would like it removed from the repository, please contact us and we will investigate on a case-by-case basis.

Each thesis in the repository has been cleared where necessary by the author for third party copyright. If you would like a thesis to be removed from the repository or believe there is an issue with copyright, please contact us on openaccess@leedsbeckett.ac.uk and we will investigate on a case-by-case basis. 


\title{
Migrant labour in rural tourism: continuity and change
}

\section{Key words}

Migrant labour; tourism; rural employment; recruitment; social networks.

\begin{abstract}
This paper considers the impact of the recession on the availability of migrant labour in the Yorkshire Dales and reassesses how the practice of employing migrant workers, previously explored by the author, has influenced current sources of recruitment. Findings suggest constantly evolving and altering patterns of migration shaped not just by economic and spatial factors but also socially constructed by the interactions of employers and migrants. In particular results indicate how subjective experiences and judgements made around the use of social networks can recreate as well as transform the specific use of migrant labour in each establishment.
\end{abstract}

\section{Introduction}

Since the expansion of the European Union (EU) in 2004, an average of one in ten hospitality jobs have been filled by migrant workers (McCollum et al, 2012). Research by Dench et al (2006) just 2 years after the entry of the accession countries ${ }^{1}$ suggested that migrant workers had become the preferred choice in hospitality as employers perceived them to possess higher levels of motivation and a more favourable work ethic than domestic workers. In fact so central has been their use that Baum et al (2009:2) argue that it 'has altered the character of tourism products and services' in the UK and Ireland. Moreover whereas previous migration of labour into the industry largely affected urban areas, what has been significant about the present wave is that it has spread to significantly affect employment in rural tourism as well (Devine et al, 2007a, Commission for Rural Communities (CRC), 2007). Recent estimates by the CRC suggest that around a fifth of hotel and restaurant workers in rural areas are now from abroad (CRC, 2011).

The increased use of migrant labour in the UK tourism industry in the last decade has been well documented (Matthews and Ruhs, 2007, Lucas and Mansfield, 2008, Lyon and Sulcova, 2009, Janta and Ladkin, 2009) and suggests that structural factors such as low wages, high labour turnover and a 24/7/365 culture are important drivers in this phenomenon. Though a number of studies have indicated that migrant labour is important to rural hospitality businesses (Devine et al, 2007a, Lyon and Sulkova, 2009, Cuthill, 2010) few have studied this process over time. However studying this trend is important. Firstly, patterns of migration are not static. It is estimated that only around half of all accession country migrants stay in the UK (Blanchflower et al, 2007) and recent evaluation by McCollum et al (2012) points to a sharp fall in the number of new migrants entering the hospitality industry. Secondly, their research suggests that the recession has had an uneven impact on rural and urban areas. Whereas urban employers have gained from the recession, as unemployment amongst UK young people has risen counteracting the impact of reduced migration, rural businesses have struggled to fill vacancies regardless of changed economic circumstances (McCollum et al, 2012). Furthermore economic restructuring in rural economies over time has seen a significant growth in tourism businesses (De Hoyos and Green, 2011) compounding the problems in

1 The accession countries are those that joined the EU in 2004, comprising of the Czech Republic, Estonia, Hungary, Latvia, Lithuania, Poland, Slovakia and Slovenia (known as the A8 ) together with Cyprus and Malta, and those that joined in 2007, comprising of Bulgaria and Romania. Collectively they are known as the A12. 
securing sufficient labour. However it is clear from a number of recent studies that economic factors alone do not shape migration patterns. Findlay and McCollum's (2013) research in rural economies for example shows that employer action is an important determinant in both shaping and changing particular patterns of migration channels over time. In addition Janta and Ladkin's (2013) study in the hospitality sector shows how the interaction of migrant workers with social media can also play an important role in influencing these channels. Therefore studying migrant labour over time can provide an understanding of how these dynamic processes have impacted on the patterns and processes of recruitment in a rural context.

A small scale study conducted by the author in the Yorkshire Dales two years after the expansion of the EU in 2004, found significant reliance on migrant labour by small tourism businesses (Anon, 2009). The employers in the study all reported pronounced local recruitment difficulties, citing poor service attitudes, an unwillingness to work for low wages combined with their rural location as key reasons for failing to recruit from within the UK. In contrast migrant workers, most of whom were qualified to degree level, appeared prepared to work at minimum wage levels and were perceived by employers at least to possess service skills superior to their UK counterparts, who they generally type casted as lazy and ill-suited to delivering service quality. This reinforced their reliance on migrant labour, which they perpetuated further by tapping into the workers' family and friendship networks in their home country as a source of further recruitment.

By revisiting the businesses that participated in the initial research, this follow up study examines the extent to which employers have been able to maintain their supply of migrant labour in the context of shifting patterns of migration and recessionary pressures. Its second aim is to understand how the different actors, employers and migrant workers, and their experience of recruitment and employment have shaped present patterns and usage of migrant labour, in particular the extent to which the reliance and experience of social networks, uncovered in the initial study, have helped maintain this supply.

\section{Rural tourism employers and the demand for migrant labour}

In line with industrialised nations elsewhere England's rural economies and their social make up have changed considerably over the last few decades. Employment in agriculture and related industries has declined and there has been a population shift away from urban to rural areas most notably by families and the retired (Defra, 2004). Concurrently employment in industries such as services and in particular tourism has increased significantly (de Hoyos and Green (2011) coinciding with a drift away from rural areas by the young workers on which tourism has traditionally relied. This has created significant recruitment problems for rural employers, exacerbated further by difficulties not encountered by those in towns; lack of public transport and a process of gentrification pushing up housing costs (CRC, 2011, Chappell et al, 2009). Some of these problems are compounded in National Parks such as the Yorkshire Dales, where ironically tourism reinforces this exodus as house prices tend to be much higher than in other rural areas (National Parks, n.d). Employment in rural areas has therefore come to be associated with work that is generally low skilled, poorly paid, casualised and with poor career prospects (Green, 2003). Young workers in particular appear to be affected by these changes. According to Shucksmith (2004) their employment choices have become split. Their choice is either work that is well paid and with career prospects but likely to be in urban areas, or work in rural areas that is poorly paid, has few prospects and is likely to be insecure. The reality of work in sectors like tourism can help shape these choices.

Key reasons cited for the employment of migrant labour are that they are prepared to accept jobs that local workers reject (Piore, 1979 and Massey et al, 1993). The cause of this is in tourism is not hard to locate. The sector nationally displays pay levels that rank amongst the lowest in the UK economy (Low Pay Commission, 2010) and contains features that according to Baum (2007) have remained essentially unchanged since Wood's (1997) analysis of hospitality work as exploitative, degrading, unpleasant and insecure. According to Lucas and Mansfield (2008) these factors provide a key explanation for the employment of migrant workers as UK workers shun work in the sector in favour of work elsewhere. The movement of labour therefore is not regarded as a spontaneous process but relies fundamentally on employer strategies within particular industries and segments of the labour market. Labour shortages may 
be part of the explanation but labour cost minimisation is regarded as a key driver for patterns of inward migration (Piore, 1979, Fellini et al, 2004, Rodriquez, 2004, MacKenzie and Forde, 2009). The choices that drive local and migrant workers to particular industrial sectors and geographical areas can be further understood by the hierarchies of good and bad jobs that Piore (1979) and Waldinger and Lichter (2003) argue are created by employers. Their analysis helps us to understand how tourism employers and the decisions they make over wage rates creates a hierarchy of preference that determines who is likely to be employed or not. Local and migrant workers orientations to work are likely to be different with each using their home country as an initial indicator of what is a good or bad job. For example Jentsch et al's (2007) study on the use of migrant labour into rural Scottish businesses such as hospitality found that the choice of sector or location was not the key driving point but the availability of work and the comparatively high wages in the Scottish Highlands. Even for university graduates an unskilled hospitality job was better paid than a professional job back home and despite this mismatch employers lauded them for their readiness to work long hours and take on any job given.

This analysis is helpful in explaining patterns of migration and how, depending on the specific economic context, these patterns may shift. However research by Findlay and McCollum (2013) indicates how these patterns are also socially constructed and that the input of employers, migrants and recruitment agencies over time can both produce, reproduce and also alter their exact make up. This indicates that it is important to understand both how labour is sourced as well as how the process this creates can in itself shape consequent patterns of recruitment.

\section{Maintaining the supply through social networks}

Evidence for how this labour is sourced provides a mixed picture and appears to have evolved and altered over time. Employers have been instrumental in shaping the patterns of migration; initially through recruitment agencies (for example in London by channelling migrant workers into low wage service work (McDowell et al, 2008)) but increasingly overtime via migrants own networks of family and friends (Findlay and McCollum, 2013). Studies focussing on migrant labour in both urban and rural areas of the US and UK have found strong evidence of this in industries such as hospitality (Devine et al, 2007, Janta el al 2011b, Waldinger and Lichter, 2003). Research carried out by Sumption (2009:6) in the UK found that Polish workers were 'dramatically' more likely to find jobs in this way and that as the supply of workers from Poland increased so did recruitment through family and friends with informal referral increasing by 40\% since EU enlargement in 2004 (Sumption, 2009). Indeed White and Ryan's (2008) study into the use of social networks found that they can be created rapidly, often within just six months of the first migrant worker being employed. Accordingly, their use seems particularly suited to the highly volatile nature of tourism employment

Social networks also incur advantages for prospective migrant workers, influencing their decisions to migrate and providing them with an important source of social capital. Networks become conduits of knowledge about prospective employment opportunities and can offer emotional support, companionship and socialisation opportunities in and out of work (Boyd, 1989, Ryan et al, 2008). The risks therefore that might be associated with migration, such as homesickness etc., may be reduced where migration is seen as short-term and experimental (White and Ryan, 2008) as is the case in much of tourism. Devine et al's (2007b) study in the Northern Ireland hotel sector and Janta et al's (2011b) research in UK hospitality found that networks allow for easy access both into and quickly out of employment and facilitate their adaptation to a new culture providing sources of comfort and emotional support.

The nature of social networks therefore would suggest that current migrant workers have become fundamental in shaping future patterns of migration. However research indicates that the decisions employees make about which of their friends or family to recommend is very much based on what they believe their employers perceive a 'good' worker to look like (Findlay and McCollum, 2013). As MacKenzie and Forde (2009) have indicated this perception amongst employers can change overtime with focus shifting away from one group of nationals towards another depending on who is seen to have the attributes most valued at any one particular time. Migrant workers clearly do interact with the process though as is shown by Janta and Ladkin's (2013) research into the use of social media. Their findings show that the internet can be a useful tool for prospective migrant workers with sites either 
recommending or warning them about prospective employers based on the views of migrant who have already worked there.

The features of social networks can therefore make them appear attractive to both employers and employees. However recruitment via social networks can also lock migrants into low wage employment (Sumption, 2009) and their survival depends not only employers' use of them but the benefits they are seen to accrue workers. Perceptions of migrant workers to their employment conditions in tourism is ambiguous On the one hand the sector is seen by migrants as providing a quick and easy route into low skilled employment, affording opportunities to develop language fluency and allow them to save money in a relatively short period of time by working long hours and earning tips (Baum et al, 2007, Janta et al, 2011a). Yet simultaneously some of these same features also illicit negative responses; dissatisfaction at the under-utilization of their skills (migrant workers in the UK hospitality industry tend to be highly qualified (Janta, 2011) caused by a lack of language fluency (Baum et al, 2007), or, where lack of fluency is seen to be used by employers as an excuse not to promote (Wright and Pollert, 2006), a long hours, low pay work culture that is regarded as demeaning and physically onerous, combined with instances of discrimination and maltreatment by employers (Wright and Pollert, 2006, Baum et al, 2007, Janta et al, 2011a). Simultaneously changing economic conditions back home may also influence the particular structure of social networks.

Migration therefore is not a static process but evolves over time influenced by factors that are not just economic but culturally and socially determined as well.

\section{Research approach}

The advantages of studying the use of migrant workers in the same workplaces across time is precisely that it can facilitate a greater insight into the dynamic nature of shifting patterns of migration and how the role of different actors, circumstances and location helps shape them. Using a qualitative approach to research can facilitate this process in that it allows the researcher to make sense of and interpret such phenomena in their natural setting (Denzin and Lincoln, 2008). Adopting such a qualitative approach however makes it impossible to replicate specific findings as it is not feasible to 'freeze' the social setting (Bryman, 2012: 390) but has the advantages of presenting authenticity (Cohen et al, 2000). This authenticity is best understood by drawing on the experiences and perceptions of both employers and migrant workers and understanding the context in which migratory patterns of recruitment are produced, reproduced or altered.

Research on the use of migrant labour in the Yorkshire Dales tourism industry was initially carried out in 2006 (Anon, 2009). Four tourism businesses, containing a total of six individual units, were selected through referral by employers and previous personal contact by the author.

All four businesses agreed to participate in the follow up study and semi-structured interviews were conducted in the spring of 2010 with four owners/managers and 20 migrant workers. Descriptions of each of the businesses, their change in size from the initial research and numbers of employees are presented in table 1. Significant shifts in customer demand across time means that these employment figures can only be correct at the time of research.

The migrant workers interviewed came from a mix of nationalities, the largest group being Polish, together with Latvian, Slovakian, Bulgarian, Austrian, Canadian and Dutch workers. All were employed on a full time basis with length of tenure ranging from one month to seven years and a combined average of 15 months of continuous service. All of those interviewed were under 30 and there was an equal spread of male and female workers. Of this group two had become supervisors and therefore were able to comment on both sides of the employment relationship. With the exception of the HR manager in the largest establishment, all the managers/owners participating in the study had taken part in the initial research. All of the workers who took part had arrived since 2006 except one who had participated in the first study. Potential migrant worker interviewees were identified by the employer with the possibility therefore that those selected might be trusted to talk positively about their experiences. A more likely 
reason though was simply their availability on the day. Interviews were conducted over a four day period lasting between one and two hours.

All interviews were recorded and transcribed and a thematic analysis (Braun and Clarke, 2006) was used to analyse the findings. This demonstrated continued reliance on migrant workers, shifts in the recruitment patterns toward different nationalities and problems encountered by both employers and migrant workers based on their experiences. Some of the findings that were uncovered might be difficult to categorise as themes, such as the negative reactions by two employers and by two migrant workers on their experience of social networks, but according to Braun and Clarke (2006: 87) this simply represents a more 'nuanced' pattern. Quotes have been used to illustrate some of the findings and can be a useful means to illuminate how participants in research make sense of their world (Corden and Sainsbury, 2006). All quotes cited in the findings have been reported verbatim.

\section{Research findings}

\section{Employers' continued and changing use of migrant labour}

Findings from each of the businesses indicate no significant change in the volume of migrant workers employed, with only Business $\mathrm{C}$ reporting a reduction in the proportion of migrants from $70 \%$ to $30 \%$. Three of the businesses did report difficulties in recruiting from abroad, in particular from Poland; however the impact this has had is not significant and is primarily offset by recruitment through social networks and word of mouth. The anticipated impact the recession might have had on the availability of workers from the UK does not appear to have occurred either. Business A for example reported being baffled that despite the daily news being full of stories about increasing unemployment any job adverts placed still resulted in no applications. Typical of the responses was an almost total absence of control over the recruitment process and a feeling that this was due almost entirely to the location:

'being rural has a huge impact... it's often difficult to get people to come and work here unless they live in, because you almost exhaust the local workforce, we may have a pool of casual labour, but with skilled labour such as chefs, you've actually got to get people from further away.' (HR manager, Hotel Business B)

Combined with significant transport problems (buses to the nearest town run just twice daily and not at all on a Sunday) these factors significantly restrict the access they have to potential employees and appear to have contributed to a specific blend of employment. This mix is created not by any strategic planning on behalf of the employers but by an almost accidental coincidence of factors. Migrant workers who come to this country both need to and are prepared to work full-time. Part-time and casual positions are filled by local school and returning university students whose availability more or less neatly matches the start and finish of the local tourist season. A small number of local women with children also supplement this pool during periods of high demand. Where the recession has had an impact on demand this has resulted in a readjustment of part-time and casual numbers with no significant impact on the volume of migrant workers employed.

The recruitment approach of employers therefore seems largely reactive and is characterised by a sense of helplessness reflected in other rural studies (see for example Jentsch et al, 2007). An inherent lack of control amongst small tourism businesses over the recruitment process (Walmsley, 2004) is likely to exacerbate this. However given these constraints there is evidence that employers in the study have also played a role in shaping specific patterns of migration in ways discussed in the literature review.

Prioritising of certain nationalities takes place and appears based on stereotypical notions of appropriate work ethic and representations of the 'good worker' mentioned elsewhere (MacKenzie and Forde, 2009, Finlay and McCollum, 2013). For example the chance recruitment of a Canadian worker, who came to Hotel Business C from another hotel in the Dales, led to the appointment of 4 further Canadian workers as the first employee had proved to be very competent at her job and in the words of the owner she 'assumed the rest would be'. Similarly an initial chance conversation between the owners of Hotel Business A and another local business, who had had positive experiences with Bulgarian employees, led her to initially 
try a number of workers. Bulgarians now make up almost the entire foreign workforce in that business. Specific filtering of prospective employees is further carried out by an agency in Bulgaria (whose costs are born by the employee at a cost of $£ 600$ each) based on a strict set of criteria from the hotel and interviews.

Therefore although numerically there is no substantial difference with the first study, the most significant differences are associated with the change in composition of nationalities and how these are be produced by employer action. Polish remains the key nationality, but as in Businesses A and B there has been a shift in the use of workers from elsewhere. A key reason for this switch appears tied up with the experience of recruiting through social networks.

\section{Social networks: contradictions and dilemmas}

One of the gambles which appeared most successful in the first study was the use of networks. Although the initial research was carried out just two years after the opening up of the EU all of the businesses in the study very quickly starting utilising workers networks of family and friends and thus perpetuated the recruitment of particular nationalities, most notably Polish. With the exception of the Bulgarians and Canadians, all of the workers interviewed in the present study were recruited in this manner. Recruitment through their own website, advertising locally or through a job centre resulted in almost negligible returns. Recruitment through networks on the other hand was regarded as both a cheap and reliable alternative where employees could be trusted to recommend those who fitted into the organisation:

'Trust can come through a family connection. We've got brothers/sisters that work here; two sets of sisters and four Polish brothers who have two more sisters back in Poland that are also likely to come. Often it's word of mouth, it's a small world, somebody leaves, tells friends it's a great place to work ... word of mouth is often the best way, it's as if you're wanting a skilled tradesman, it's often best if you hear about someone through recommendation rather than pay extortionate agency fees. We see things quite black and white. We say that if you have to pay $£ 2000$ to recruit someone then that's how many covers we have to sell in our restaurant or that's how many cups of coffee we have to sell' (HR Manager, Hotel business B)

Referral of a different nature also occurred through knowledge passed on by the accidental recruitment of particular workers and in some cases has led to the establishment of further networks. For example a Dutch worker with experience and knowledge of the industry internationally has led them to a whole array of further sources to tap into. The Austrian workers in the hotel were initially accessed through his knowledge of an international job search engine specialising in hospitality recruitment. Additionally his knowledge of hotel schools in Holland, Belgium and France has supplied them with a number of internship students. Recruiting through social networks then has become the single most effective way for the business to source its migrant workforce. However whereas the initial study reported only positive views on this form of recruitment, four years on the attitudes towards these networks is more complex. Businesses A and C's initial experience of recruiting a mainly Polish workforce through friends and family contacts was wholly positive. Their work ethic was seen to be exemplary and no amount of work, according to employer A, was seen to be beneath them. Their national identity was celebrated in the bar where banners of the Polish flag decorated the public area. The views expressed in the present study however are markedly at odds with these and appear tied up with the social consequences of employing young migrant workers through networks:

'They (the Polish workers) didn’t treat it as an official job. I just found it too holiday campish. It was like, 'oh I've got a friend' and they come and work for you and they all just take the mickey out of you. They had their own set of rules, they didn't treat it as an official job offer they treated it like 'oh my friend's got me this job and it's really good and I've got so many hours and so much money' and it just became as if they were running the show a bit rather than us running the show ... letting the bar stay open later than they should have done, slipping into what they wore uniform wise, running parties. .. they also had friends at other hotels and would get together and party’ (Owner/manager Hotel Business A) 
This perceived of loss of disciplinary control was shared by Hotel Business C whose owner expressed concern over the excessive socialising of a group of Polish employees. It is worth noting that no attempt was made in any of the businesses to help them socialise and integrate with the wider community. In both cases these negative perceptions have led to a shift in recruitment to target the different nationalities previously discussed. McDowell et al's (2008: 761) study of migrant labour in a London hotel similarly found that the formation of so called 'cliques' resulted in changes in national stereotyping by employers and was responsible for wholesale shifts in which nationality to recruit. Intrinsic in social networks therefore is that they can be both advantageous to employers by activating a constant replenishment of labour but can simultaneously form what Waldinger (1997) has termed social closure where partial control over labour is passed from employer to employee. His research demonstrates that intrinsic to networks is that once in place they are hard to uproot and are structured by history and a continuity of relations that occurs irrespective of the business. This tendency towards social closure and clique forming may arguably be more marked in rural locations and amongst tourism businesses. Remoteness denies employees access to leisure and social facilities (Cuthill, 2010) and these are then substituted by the social facilities offered by the establishment in which they work.

Interestingly mixed experiences towards the use of networks are also shared by the migrant workers interviewed and may be similarly associated with issues of social closure. As research by Janta et al (2011b) has indicated, for the majority of employees sharing their working and in some cases living environment with family, friends and others who have a similar cultural heritage offers them a degree of comfort and support. To some extent employment is a known quantity prior to arrival, and settling in is easier when facilitated by ties or a cultural attachment that exists beyond the workplace. The ability to converse comfortably in their own language, particularly initially, was cited by a number of employees as an important factor in helping them to acclimatise. However as one of the Austrian waiters explains, this can create paradoxical effects,

'When I first came here there was just one other Austrian guy. It was good because I don't want to speak German but actually I was glad there was another person because sometimes it is nice that you have somebody who can talk in your mother language but now we are four people from Austria. It's too much, because I can stay in Austria if I want to speak German and we are all working in the same department and we are all speaking our own language ... and they (other hotel employees) speak Polish with each other so we don't understand them, so it's like, are they talking about us? It makes it more difficult because you can't communicate with each other. On my days off I speak German and it’s not really why I came’ (Austrian waiter hotel Business B)

Here social networks become restrictive rather than supportative and prevent what Ryan et al (2008) have described as bridging beyond the confines of the network as well as creating feelings of mistrust.

Rural location, combined with employer inaction, can serve to exacerbate the potential for some of these negative outcomes to arise as the chances to establish relationships beyond the confines of the network is already much more limiting. For others in the study the very fact of recommending employment opportunities to friends and family back home can create an unforeseen additional burden both inside and outside of work. In this case cultural attachments become burdensome as employees are required to take responsibility for the friends they have recommended far beyond the scope of their job. Both workers at restaurant D indicate ways in which such problems can occur:

'Lots of them they don't know English. You have to be for a long time translator and it's hard. Go to bank, national insurance, Home Office with them. It's a job for which no one will pay you. You do it because you just want to help. You are in the middle. You are translator ... If my boss say to them go clean the garden and they don't show you properly, then my boss come to me, can you explain to her again to go and clean properly. I have to go and do that. I am the bad person. I don't want to do that anymore' (Polish waitress, Restaurant D)

'After she (her friend) started working she was lazy and I feel wrong. It's not easy. After three days they call me to the office and tell me what she's doing. Would you speak with her and show her how cleaning properly. I told her everything. She now cleaning properly. . I think the last person will be the last one.' ((Slovakian waitress, Restaurant D) 
In this case the advantage is with the employer. Not only has the social network resulted in the cheap replacement of labour but initial members can also be used to pass on their skills and supervise others performance (Portes, 1998). For employees though this involves clear risks. In effect they are converted into unpaid trainers, translators and mentors and therefore may question the value of social network referral. It is worth noting that the language classes offered by all of the businesses in the initial research were no longer running, with employers citing lack of funding and interest as reasons for this.

\section{Migrant workers' perception of work: continuity and change}

The reasons given by those migrant workers from Eastern Europe in seeking work in the UK also appear largely consistent with those in the previous study, lack of work and or low wages in their home country combined with a motivation to learn English;

'The people at home they working so hard but the money, it's not enough. It's still better working here than in Hungary. The work is better here, the money is much better. In Hungary I think the people working much harder that here in England. I also learn the language here.' (Slovakian waitress in restaurant D who had previously worked in Hungary).

The economic imperative driving migration decisions do not appear to be shared by those workers from the wealthier economies of Austria and Canada. Far from being shaped by economic factors, their motivations to work abroad are much more consistent with the opportunity to travel, experience working abroad and, in the case of the Austrian workers, to develop their English language skills:

'I just do it because I like to work abroad, I like to learn the language and I want to make some experience in a foreign country, but it's still I earn more money in Austria, it's not the reason I'm here for the money just really the experience. The difference in wage is about $£ 400$ a month for the same. In Austria it's important if you speak a second language' (Austrian waiter, Hotel Business B)

Economic factors however appear largely responsible for shaping the decisions of these workers to return home where wage and job opportunities are seen to be greater than in the UK. Migrants from Eastern Europe however appeared more split in terms of their decision to return. Finch's (2009) research suggests that re-migration is more likely to occur due to social factors such as missing family and friends and a simple yearning for home and these findings are reflected in this study with most Eastern Europeans intending at some stage to return. However for some both their economic, social and cultural attachments appear to have shifted to the UK:

'We (including her Polish husband) have everything here now. When we work one year we bought car, now we have another New Year and this car in Poland is very expensive. Last year we been in Tunisia for one week. I think in Poland I never go to Tunisia. It's different life here, if you have here your salary is $£ 1000$ and you buy beer and have car, you have money left, but say in Poland you have $£ 1000$, this $£ 1000$ only goes for rent and in Poland the salary is very low' (Polish housekeeper in Hotel Business B who had worked in the Dales for four years).

'I'm not living in Poland now for seven years. Seven years is a long time and a lot of things have changed now. I have to start everything new when I came here. I start new job, I learn new language, when I'm back in Poland it will be the same, I have to start everything again. Only good reason would be I know Polish.' (Polish waitress who had worked in Restaurant D for seven years)

A number of studies both in tourism and in low paid work have explored these shifting allegiances and points of reference for migrant workers between their home and destination countries. Janta (2011) has shown that over half of those working in hospitality plan to stay but also indicates that workers constantly re-evaluate their plans. A further body of academic work indicates that the longer migrants stay in the receiving economy the more their attachments and economic points of reference start to shift (Bauder, 2006, MacKenzie and Forde’s, 2009, Piore, 1979 and Waldinger and Lichter, 2003). The initial economic 
advantage gained in moving abroad slips away, as their point of reference becomes the wages and opportunities afforded by work in the UK. The reality of this can be stark, as is indicated by the frustration felt by some of the Eastern European workers interviewed. Despite higher wages and better standards of living in the UK, the Polish housekeeper who now lives with her husband in the Dales, has a primary school age child and has recommended jobs in the hotel to friends from back home, still yearns for Poland, missing family and friends and the 'Polish tradition'. In addition, her lack of language fluency and the Polish degree which she feels is unrecognised by potential employers in the UK ghettoises her into low wage employment. Eade's (2007) work suggests that migrants constantly revaluate their intentions to stay or go depending on prevailing social and economic conditions. Having children opens up the possibility of accessing local networks and the chances of forging relationships beyond work (Ryan et al, 2008) and may complicate allegiances further.

\section{Conclusion}

Studying the recruitment of migrant workers over time has uncovered a picture that is simultaneously multi-faceted and contradictory and would appear to support Ladkin's (2011) assertion that negotiating tourism employment and interacting with the labour market is complex for both tourism employers and migrant workers. Findings from this research suggest that this complexity may be more marked where the employment of migrant workers takes place in a rural setting and where the size of the business is too small to influence a more formal approach to sourcing employees. The worsening economic environment should favour recruitment from within the UK but spatial factors and a low cost attitude to labour in the sector as a whole have restricted the ability of employers in the study to take advantage of the wider pool of labour available to them. Instead employers rely on an almost serendipitous mix of migrant and casual local labour to sustain them.

Superficial appearances belie the fact that even in rural setting employers are also active in creating, shaping and altering specific channels of migration depending on their subjective experiences of recruiting migrant labour over time and the stereotypical attitudes that they use to determine the suitability of one nationality over another. This is most clearly illustrated by employers use and experience of social networks and how employers have either continued their reliance on them or abandoned them altogether. For two of the businesses recruitment through referral continues to be a trustworthy and above all cheap method from which to replenish the supply of labour. However this is not the case for the remaining businesses whose experience of networks has led them to completely reorientate their recruitment methods and the nationalities on which they have previously relied. Whereas in the first study they were clearly seen as mechanisms that could support management, these employers now regard them as a threat to their overall sense of control. According to management the network has become an entity in itself, isolated from managerial authority in ways described by Waldinger (1997) and able to act for itself and set its own rules of conduct. To reassert control management have switched their recruitment to agencies. These act as further agents in shaping migratory patterns as they vet and select candidates based on criteria passed on by management and therefore determine which migrant worker joins the business or not.

Findings indicate that for migrant workers the function of social networks can be similarly double edged. Pre-existing ties can provide initial employment and provide important mechanisms to help workers settle in but can also tie them into low wage work as well as lessening the chances of language acquisition and formation of cultural attachments elsewhere. As the findings indicate allegiances to stay or return home are therefore not always predicable and fluctuate in ways suggested by other studies.

In addition the very act of recommending someone can become burdensome and may lead individuals to stop network referral altogether. To a lesser extent then migrant workers also play a role in shaping the specific patterns of migration that occur in workplaces and therefore supports Findlay and McCollum's (2013) research that these patterns are not just economically driven but also socially structured. Their research, which focused on the rural food production, processing and hospitality industries, presents evidence that the economic, social and spatial structures that produce, create and shape particular channels of migration also interact with each other to create the emergence of specific patterns over time. Though the pattern in the Dales study is less clear, referral in general is still the main form of recruitment and is rooted in the labour economics of the industry and the geographic isolation of the Dales. That 
referral takes place primarily through network connections but also the swapping of local employer knowledge and serendipitous recruitment of workers whose own knowledge opens up the possibility of further routes to migrant labour. Findings in this study suggest that the survival of such channels is not just dependent on international fluctuations in migration but also the subjective experiences and perceptions of those involved.

This points to a clear need for employers to be more interventionist and proactive in shaping migrant workers employment experiences. Despite the obvious restrictions posed by rural location and size much more could be done to create a more stable and settled workforce. For this to take place Ryan et al's (2008) study suggests that forming relationships outside the immediate network with others in the locality is vital. Devine et al's (2007a) research further indicates that where employers do take such steps, by for example providing social activities helping to connect migrant workers to the wider community, successful integration is more likely. In addition language competency needs to be more systematically addressed. Cuts in English language funding have made it more difficult for employers in the study to maintain this important provision and changes are clearly needed at a national level to address this. However rural employers could group together in local communities within the Dales to provide centralised access to language classes for migrant workers. This would not only help those workers in acquiring language skills but depending on the focus of the teaching and the mix of different nationalities in the classes might also help workers to integrate. Baum (2012) has also argued for greater recognition at a national level of different international qualifications. For those migrants in the study who feel stuck in lower level employment, despite possessing qualifications that could potentially lead them to more skilled work, this would seem a priority.

The specific findings of this paper demonstrate that the shaping and altering of migration patterns in rural tourism is more subtle than is suggested by tourism based studies elsewhere and have helped to facilitate a more rounded and nuanced understanding of the relationships between migrant workers and rural employers based on past recruitment decisions. The complexity of these relationships however should not deter employers from seeking more formalised ways of assisting the social integration of migrant workers. Given the erratic nature of tourism labour supply and demand this would seem to be a priority.

\section{References}

Anon, (2009). Migrant workers in the Yorkshire Dales: A temporary solution?, in Thomas, R. (Ed.), Managing Regional Tourism: A case study of Yorkshire. England: Great Northern: Ilkley.

Bauder, H. (2006). Origin, employment status and attitudes towards work: immigrants in Vancouver, Canada. Work, Employment and Society 20 (4): 709-729.

Baum, T. (2007). Human resources in tourism: still waiting for change. Tourism Management 28: 13831399.

Baum, T. (2012), Migrant workers in the international hotel industry, International Migration Paper No. 112, Geneva: International Labour Office. Available at http://vnaid.org/en/attachments/902_Migrant\%20workers\%20in\%20the\%20international\%20hotel\%20ind ustry\%202012\%20ILO.pdf (accessed 12 September 2013).

Baum, T., Dutton, E., Karin, S., Kokkranikal, J. Devine, F. and Hearns, N. (2007). Cross cultural diversity in hospitality work, Cross Cultural Management: An International Journal 14 (3): 229-239.

Baum, T, Devine, F and Hearns, N. (2009). Migrant communities in the representation of tourism destination and products, Tourism Culture and Communication 9 (1/2): 1-5.

Blanchflower, D., Salaheen, J and Shadforth, C. (2007). The Impact of the Recent Migration from Eastern Europe on the UK economy. Institute for the Study of Labour. Discussion paper No. 2615. Available at 
ftp://ftp.iza.org/dps/dp2615.pdf (accessed 18 June, 2012).

Boyd, M. (1989). Family and Networks in International Migration: Recent Developments and New Agendas. International Migration Review 23 (3): 638-670.

Braun, V. And Clarke, V. (2006), Using thematic analysis in psychology, Qualitative Research in Psychology 3; 77-101

Bryman, A. (2008). Social Research Methods. $4^{\text {th }}$ edition. Oxford University Press: Oxford.

Chappell L., Latorre, M., Rutter, J. and Shah, J. (2009). Migration and Rural Economies: Assessing and addressing risks. Economics of Migration Paper 6. Available at http://www.ippr.org.uk/publicationsandreports/publication.asp?id=670 (accessed 13 January 2010).

Cohen, L. , Manion, L., Morrison, K. (2000). Research Methods in Education. $5^{\text {th }}$ edition. Routledge Falmer: London

Corden, A. and Sainsbury, R. (2006), Using verbatim quotations in reporting qualitative research: researchers' views, ESRC 2136. Available at

http://www.york.ac.uk/inst/spru/pubs/pdf/verbquotresearch.pdf (accessed 19 May 2014).

Commission for Rural Communities (2007). A8 migrant workers in rural areas, Briefing Paper, Commission for Rural Communities. Available at http://www.ruralcommunities.gov.uk/files/A8\%20migrant\%20workers\%20in\%20rural\%20areas2.pdf (accessed 25 January 2008).

Commission for Rural Communities (2011). International Migration and rural economies, Commission for Rural Communities. Available at http://www.communities.gov.uk/documents/corporate/pdf/1854822.pdf. (accessed July $13^{\text {th }}, 2012$ ).

Cuthill, V. (2010), Hospitality Workers’ Perceptions of Working with People of Different Nationalities and Living in the Highlands, A report from the Global Welcome? Migrant Workers, Service Cultures, Tourist Places study 2009-2010, ESRC. Available at http://www.migrantworkersnorthwest.org/pdfs/Report-Highlands..pdf (accessed 18 July, 2012).

Defra (2004), Social and Economic Change and Diversity in Rural England, Available at http://www.swslim.org.uk/documents/themes/LT17-rwp-review-birkbeck.pdf (Accessed May 11, 2014).

Dench, S., Hurstfield, J. Hill, D. and Ackroyd, K. (2006). Employers' use of migrant labour, Home Office RDS Online Report 04/06. Available at www.homeoffice.gov.uk/rds/pdfs06/rdsolr0406.pdf (accessed 21 January 2007).

Denzin, N.K and Lincoln, Y.S (Eds), (2008). Collecting and interpreting qualitative materials. $3^{\text {rd }}$ edition, Sage: Thousand Oaks, California.

Devine, F., Baum, T., Hearns, N., and Devine, A. (2007a), Cultural diversity in hospitality work: the Northern Ireland experience, International Journal of Human Resource Management, 18 (2): 333-349.

Devine, F, Baum, T., Hearns, N and Devine, A. (2007b). Managing cultural diversity: opportunities and challenges for Northern Ireland hoteliers. International Journal of Contemporary Hospitality Management 19 (2): 120-132.

Eade, J. (2007). Class and ethnicity: Polish Migrant Workers in London: Full Research report. ESRC End of Award report, RES-000-22-1294. Swindon: ESRC. Available at http://www.esrc.ac.uk/myesrc/grants/RES-000-22-1294/outputs/read/89551447-b4fb-4028-8c2b-08aab6b602c4 (accessed 25 June 2012). 
Fellini, I., Ferro, A. and Giovanna, F. (2007). Recruitment processes and labour mobility: the construction industry in Europe. Work, Employment and Society 21: 277-298.

Finch, T., Laterre, M. Pollard, N. \& Rutter, J. (2009). Shall we stay or shall we go? Re-migration trends among Britain’s immigrants. Institute of Public Policy Research: London. Available at http://www.ippr.org/ecomm/files/shall_we_stay.pdf (accessed 20 June 2010).

Findlay, A. and McCollum, D. (2013), Recruitment and employment regimes: Migrant labour channels in the UK's rural agribusiness sector, from accession to recession, Journal of Rural Studies 30 (April): 1019.

Green, A.E. (2003), Rural labour markets, skills and training. Report to DEFRA seminar, $15^{\text {th }}$ April 2003. Institute for Employment Research, University of Warwick.

De Hoyos, M. and Green, A. (2011). Recruitment and retention issues in rural labour markets. Journal of Rural Studies 27 (2): 171 - 180.

Janta, H. and Ladkin, A. (2009). Polish migrant labour in the hospitality workforce: implications for recruitment and retention. Tourism, Culture and Communication 9 (1/2): 5-15.

Janta H. (2011) 'Polish migrant workers in the UK hospitality industry: Profiles, work experience and methods for accessing employment'. International Journal of Contemporary Hospitality Management, 23 (6): 803-819.

Janta, H. Ladkin, A., Brown, L. and Lugosi, P. (2011a). Employment experiences of Polish migrant workers in the UK hospitality sector. Tourism Management 32 (5): 1006-1019.

Janta, H., Brown, L, Lugosi, P and Ladkin, A. (2011b). Migrant relationships and tourism employment. Annals of Tourism Research 38 (4): 1322-1343.

Janta, H. and Ladkin, A. (2013), In search of employment: online technologies and Polish migrants, New Technology, Work and Employment 28 (3): 241-253.

Jentsch, B., de Lima, P. And MacDonald, B (2007), Migrant Workers in Rural Scotland: "Going to the Middle of Nowhere”, International Journal of multicultural Societies 9 (1): 35-53.

Ladkin, A. (2011). Exploring tourism labor. Annals of Tourism Research 38 (3): 1135-1155.

Low Pay Commission (2010). National Minimum Wage. Low Pay Commission Report 2010. Available at http://www.lowpay.gov.uk/lowpay/report/pdf/LPC_Report_2010.PDF (accessed 23 April 2010).

Lucas, R. and Mansfield, S. (2008). Staff shortages and immigration in the hospitality sector. A report prepared for the migration Advisory Committee. Migration Advisory Committee: London. Available at http://www.researchonline.org.uk/sds/search/download.do?ref=B13274

(accessed 25 June 2012).

Lyon, A. and Sulcova, D. (2009). Hotel employer's perception of employing eastern European workers. A case study of Cheshire, UK. Tourism, Culture and Communications 9 (1/2): 17-28.

MacKenzie, R. and Forde, C. (2009). The Rhetoric of the 'Good Worker' versus the Realities of Employers' Use and the Experiences of Migrant workers. Work, Employment and Society 23 (1): 142159.

Massey, D, Arango, J., Hugo, G., Kouaouci, A., Pellegrino, A. and Edward Taylor, J. (1993), Theories of International Migration: A Review and Appraisal, Population and Development Review, 19 (3), 431-466. 
Matthews, G. and Ruhs, M. (2007). Are you being served? Employer demand for migrant labour in the UK's hospitality sector. Working Paper No.5. Compass: University of Oxford. Available at www.compas.ox.ac.uk/publications/Briefings/hospitality\%20briefing.pdf (accessed 17 February 2008).

McCollum, D, Cook, L., Chiroro, C., Platts, A., MacLeod, F., and Findlay, A.(2012). Spatial, sectoral and temporal trends in A8 migration to the UK 2004-2011: Evidence from the Worker Registration Scheme. Centre for Population Change, Paper No.17. Available at http://cpc.geodata.soton.ac.uk/publications/2012_Spatial_sectoral_and_temporal_trends_in_A8_migratio n_WP17_McCollum_et_al.pdf (accessed 17 July 2012).

McDowell, L., Batnitzky, A. and Dyer, S. (2008). Internationalization and the Spaces of Temporary Labour: The Global Assembly of a Local Workforce. British Journal of Industrial Relations 46 (4): 750 770.

National Parks (n.d.), Planning and affordable housing, National Parks. Available at http://www.nationalparksengland.org.uk/home/policy/planning-and-affordable-housing (accessed May 7 2014).

Portes, A. (1998), Social Capital: Its Origins and Applications in Modern Sociology. Annual Review of Sociology 24: 1-24.

Piore, M.J. (1979). Birds of passage. Migrant labor and industrial societies. Cambridge University Press: London.

Rodriquez, N. (2004). “Workers Wanted”: Employer Recruitment of Immigrant Labor. Work and Occupations 31 (4): 453-473.

Ryan, L., Sales, R., Tilki, M. and Siara, B. (2007). Recent Polish Migrants in London: Social networks, transience and settlement. Available at http://eprints.mdx.ac.uk/4181/1/Ryan_et_al._Recent_Polish_Migrants_in_London_2007.pdf (accessed 20 June 2012)

Ryan, L., Sales, R., Tilki, M. and Siara, B. (2008). Social networks, social support and social capital, Sociology 42 (4): 672-690.

Shucksmith, M. (2004), Young people and Social Exclusion in Rural Areas, Sociologica Ruralis 44 (1): 43-59.

Sumption, M. (2009). Social networks and Polish Immigration to the UK, Economic of Migration Paper 5. Available at

http://www.ippr.org/members/download.asp?f=\%2Fecomm\%2Ffiles\%2Fsocial_networks_polish_immigr ation.pdf (accessed 25 March 2010).

Waldinger, R. (1997), Social capital or social closure? Immigrant networks in the labor market, Working Paper Series, The Ralph and Goldy Lewis Centre for Regional Policy. Available at http://escholarship.org/uc/item/06z6331r (accessed 28 march 2010).

Waldinger, R. and Lichter, M.I. (2003). How the other half works. Immigration and the social organization of labor. University of California Press: London.

Walmsley, A. (2004). Assessing staff turnover: A view from the English Riviera. International Journal of Tourism Research 6: 275-287.

White, A. and Ryan, L. (2008). Polish ‘Temporary’ Migration: The Formation and Significance of Social Networks. Euro-Asia Studies 60 (9): 1467-1502. 
Wright, T. and Pollert, A. (2006). The Experience of Ethnic Minority Workers in the Hotel and Catering Industry: Routes to Support and Advice on Workplace Problems. ACAS Research Paper 03/06. Available at

http://www.acas.org.uk/media/pdf/0/b/03-06_1.pdf (accessed 12 May 2009).

Wood, R. (1997). Working in Hotels and Catering, $2^{\text {nd }}$ edition. International Thomson Business Press: London.

Table 1

\begin{tabular}{|l|l|l|l|l|}
\hline $\begin{array}{l}\text { Type of } \\
\text { Business }\end{array}$ & $\begin{array}{l}\text { Size of } \\
\text { Business 2006 }\end{array}$ & $\begin{array}{l}\text { Change in } \\
\text { Business since } \\
\mathbf{2 0 0 7}\end{array}$ & $\begin{array}{l}\text { Number of } \\
\text { employees } \\
\mathbf{2 0 0 6 / 7}\end{array}$ & $\begin{array}{l}\text { Number of } \\
\text { employees } \\
\mathbf{2 0 1 0}\end{array}$ \\
\hline $\begin{array}{l}\text { Hotel Business } \\
\text { A }\end{array}$ & One hotel & $\begin{array}{l}\text { Addition of bed } \\
\text { and breakfast } \\
\text { establishment }\end{array}$ & 33 & 47 \\
\hline $\begin{array}{l}\text { Hotel Business } \\
\text { B }\end{array}$ & $\begin{array}{l}\text { Two luxury } \\
\text { hotels and one } \\
\text { restaurant }\end{array}$ & $\begin{array}{l}\text { Addition of one } \\
\text { hotel }\end{array}$ & 120 & 200 \\
\hline $\begin{array}{l}\text { Hotel Business } \\
\text { C }\end{array}$ & $\begin{array}{l}\text { Two country } \\
\text { inns with } \\
\text { rooms }\end{array}$ & No change & 35 & 33 \\
\hline $\begin{array}{l}\text { Heritage } \\
\text { Attraction } \\
\text { Restaurant D }\end{array}$ & \begin{tabular}{l} 
One restaurant \\
\hline
\end{tabular} & No change & $\begin{array}{l}\text { 5-10 } \\
\text { (depending on } \\
\text { demand that } \\
\text { day) }\end{array}$ & \\
\hline
\end{tabular}

